\title{
Influências das políticas globais na expansão do ensino superior em Moçambique
}

\author{
MECHISSO, Guedes Basilio ${ }^{1}$
}

\section{RESUMO}

O presente artigo analisa as influências globais nas políticas nacionais, a partir da expansão do ensino superior em Moçambique. As reformas políticas de carís neoliberal a que o país foi sujeito a partir da década de 90 , com a adesão ao Banco Mundial e ao Fundo Monetário Internacional propiciaram a entrada do sector privado na educação. Poe essa via, houve um crescimento vertiginoso de novas IES na sua maioria privadas e com as IES públicas a ofertarem maior parte das vagas de ingresso em regime privado (cursos pós-laborais e a distância). Pelo carácter mercadológico, o ensino superior passou a limitar o seu acesso para todos. O referencial teórico-metodológico de análise é a Abordagem do Ciclo de Políticas de Stephen Ball e outros, sintetizado por Mainardes (2006).

Expansão. Acesso. Neoliberalismo.

\section{Influences of global policies on the expansion of higher education in Mozambique}

\section{ABSTRACT}

This article analyzes the global influences on national policies, based on the expansion of higher education in Mozambique. The political reforms of a neoliberal nature to which the country was subjected since the 1990 s, with the adhesion to the World Bank and the International Monetary Fund, provided the entrance of the private sector in education. As a result, there was a virtuous growth in new HEls, mostly private ones, with public HEls offering most of the places for admission to the private regime (post-employment and distance courses). Due to the market character, higher education started to limit its access for all. The theoretical-methodological framework of analysis is Stephen Ball's Policy Cycle Approach and others, synthesized by Mainardes (2006).

Expansion. Access. Neoliberalism.

\footnotetext{
${ }^{1}$ Doutor em Educação - Políticas e Gestão da Educação pela Universidade Federal do Rio Grande do Sul. Mestrado em Educação/Formação de Formadores pela Universidade Pedagógica - Moçambique (2013). Docente da Universidade Pedagógica - Moçambique. Email: guedes.basilio@gmail.com. Lattes: http://lattes.cnpq.br/8770947405869659. ORCID: http://orcid.org/0000-0002-4305-9710.
}

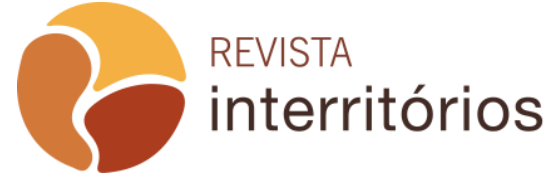

Interritórios | Revista de Educação Universidade Federal de Pernambuco, Caruaru, BRASIL | V.6 N.10 [2020] 


\section{Influencias de las políticas globales en la expansión de la educación superior en Mozambique}

\section{RESUMEN}

Este artículo analiza las influencias globales en las políticas nacionales, basadas en la expansión de la educación superior en Mozambique. Las reformas políticas de carácter neoliberal a las que estuvo sometido el país desde la década de 1990, con la adhesión del Banco Mundial y el Fondo Monetario Internacional, proporcionaron la entrada del sector privado en la educación. Como resultado, hubo un crecimiento acelerado de nuevas IES, en su mayoría privadas y IES públicas que ofrecieron la mayoría de los lugares de admisión en régimen privado (cursos posteriores al empleo y a distancia). Debido al carácter del mercado, la educación superior comenzó a limitar su acceso para todos. El marco de análisis teórico-metodológico es el Enfoque del Ciclo de Políticas de Stephen Ball y otros, sintetizado por Mainardes (2006).

\section{Expansión. Acceso. Neoliberalismo.}

\section{Influenze delle politiche globali sull'espansione dell'istruzione superiore in Mozambico}

\section{SINTESE}

Questo articolo analizza le influenze globali sulle politiche nazionali, basate sull'espansione dell'istruzione superiore in Mozambico. Le riforme politiche neoliberiste alle quali il paese è stato sottoposto dagli anni ' 90 , con l'adesione della Banca mondiale e del Fondo monetario internazionale, hanno fornito al settore privato l'accesso all'istruzione. Di conseguenza, si è verificata una crescita accelerata di nuovi istituti di istruzione superiore, principalmente istituti di istruzione superiore pubblici e privati, che hanno offerto la maggior parte dei luoghi di ammissione su base privata (post-impiego e corsi a distanza). A causa della natura del mercato, l'istruzione superiore ha iniziato a limitare l'accesso a tutti. II quadro di analisi teorico-metodologico è il focus del ciclo politico di Stephen Ball e altri, sintetizzato da Mainardes (2006).

Espansione. Accesso. Neoliberismo.

\section{INTRODUÇÃO}

O ensino superior (ES) em Moçambique data do período colonial, em 1962 quando o regime colonial português funda a primeira instituição de ensino superior, denominada primeiramente de Estudos Gerais Universitários de Lourenço Marques (EGUM), pelo Decreto o 44.530, de 21 de agosto de 1962, 
passando a denominar-se Universidade de Lourenço Marques ${ }^{2}$ (ULM), pelo Decreto no 43.799 , de dezembro de 1968, e por último Universidade Eduardo Mondlane $^{3}$, (UEM), em 1976, no período após a independência nacional. Até a independência nacional era a única IES em Moçambique e servia maioritariamente aos colonos e seus filhos. Apenas 40 estudantes, que correspondiam a cerca de $2 \%$ do total, eram negros moçambicanos (MECHISSO, 2017, p. 28).

Em 1975, a Frente de Libertação de Moçambique (FRELIMO) ${ }^{4}$, movimento que lutava pela dominação colonial, declara a independência nacional, instala um Estado monopartidário, fundamentado no marxismoleninismo e se instala o sistema socialista. Nesse período, o Estado procurou descolonizar o aparelho do Estado, nacionalizando a economia, a saúde, a educação e outros sectores, passando a ser o único provedor destes serviços e a regular a cidadania da população.

Foi neste período visível o compromisso social do Estado com os direitos sociais que se tinham recusado aos moçambicanos no período colonial. Basílio (2010, p. 19), explica que o Estado tentou reorientar as políticas sociais públicas, visando diminuir as desigualdades criadas pelo sistema colonial e abrir a possibilidade de acesso e oportunidades a todos os cidadãos, com alargamento de direitos sociais.

Em 1977, dois anos após a independência nacional, Moçambique entrou numa das guerras civis mais violentas de África, que se prolongou até 1992, movida pela Resistência Nacional de Moçambique (RENAMO) ${ }^{5}$, que se opunha ao regime da FRELIMO. Esta guerra fez retroceder o país, com a destruição de infraestruturas públicas e econômicas.

A pressão interna movida pela guerra civil, a crise económica e a seca que assolaram Moçambique em 1983, obrigaram o país, em 1984, a recorrer à ajuda do Banco Mundial e do Fundo Monetário Internacional, organismos que impuseram algumas condições para disponibilizar apoio financeiro, como o abandono do sistema socialista de economia planificada e a adopção do capitalismo.

Esta adesão abria um novo capítulo para a história de Moçambique, o período capitalista, que se inicia em 1984 e vai se consolidar a partir de 1990

\footnotetext{
2 Lourenço Marques é o nome que se chamava a capital Maputo, no tempo colonial.

${ }^{3}$ Eduardo Mondlane foi o primeiro presidente da FRELIMO.

${ }^{4}$ FRELIMO (Frente de Libertação de Moçambique) - foi fundada a 25 de junho de 1962em Dares-Salam, Tanzânia, é resultado da união três movimentos nacionalistas moçambicanos MANU, UNAMI e UDENAMO

${ }^{5}$ RENAMO (Resistencia Nacional de Moçambique) - Foi fundada em finais da década de 1970 como um movimento de resistência que viria a transformar-se em partido político após os acordos gerais de paz e a abertura ao multipartidarismo. É a principal força política da oposição em Moçambique.
}

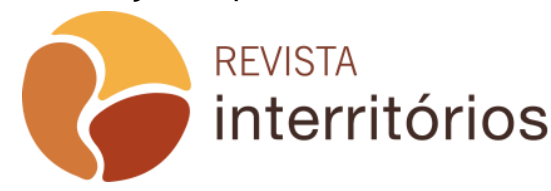


com a aprovação da nova Constituição da República (1990). O Estado intencionalmente social, formado após a independência nacional, foi afogado pelo capitalismo, obrigando o Estado a redefinir o seu papel perante a nova ideologia neoliberal e a nova conjuntura de reformas mundiais que o mundo estava atravessando, advindas da crise do capitalismo iniciada na década de 1970.

É no âmbito da adesão ao Banco Mundial e do Fundo Monetário Internacional que o país se viu obrigado a fazer reformas para o ajuste estrutural, implementou o Plano de Reabilitação Económico (PRE), um conjunto de políticas de carácter neoliberal apelidadas de Consenso de Washington ${ }^{6}$, como privatizações, liberalização da economia, redução dos gastos do Estado. O Plano de Reabilitação Económico foi implementado para reverter as tendências negativas do crescimento económico e abrangeu grandes cortes nas despesas do Governo, a descentralização do Estado, pôs fim à gratuidade de serviços oferecidos pelo Estado, bem como introduziu cobranças de taxas na saúde e educação.

O processo de liberalização económica que estava em curso no mundo e no qual Moçambique se envolveu quando da adesão ao Banco Mundial e do Fundo Monetário Internacional, assim como as condições que the foram impostas por esses organismos, vieram a influenciar não só nas relações políticas internas do país, como também na legislação, implicando em mudanças no nível constitucional e em leis de educação, entre outros documentos e na definição do papel do Estado. Emergem novos atores políticos e as políticas públicas começam a receber influência externa, de organismos internacionais. As políticas de educação em Moçambique são (re) construídas sob ditames dos compromissos mundiais de educação, como, por exemplo, a Declaração de Jomtien (Tailândia) e Dakar (Senegal), além das orientações de documentos expedidos pelos organismos internacionais, tais como o Banco Mundial, a UNESCO e a OCDE. É nesse contexto que é aprovada a nova lei de educação, a lei 6/92 do Sistema Nacional de Educação (SNE), e é aprovada em 1993, primeira lei do ensino superior, a Lei no 1/93, de 24 de junho, admitindo a criação de instituições de ensino superior privadas e a partir de 1995, se assiste-se 0 surgimento de novas instituições de ensino superior privadas, assim como a privatização do ensino superior público no período noturno, os chamados cursos

\footnotetext{
${ }^{6}$ Consenso de Washington - foi um encontro ocorrido em 1989, nos Estados Unidos da América, em Washington, que serviu de marco para a consolidação das reformas econômicas neoliberais. Foi elaborado um conjunto de medidas pelo FMI, Banco Mundial e o Departamento do Tesouro dos Estados Unidos da América, como: disciplina fiscal, redução de gastos estatais, reforma fiscal e tributária dos países, taxa de câmbio de mercado competitivo, privatizações, liberalização do comercio exterior.
}

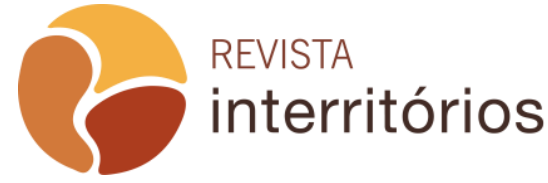


pós-laborais $^{7}$, e verifica-se ainda um crescimento exponencial da população estudantil.

De 1 instituição de ensino superior criada no período colonial, para 3 no período socialista (200\%), a partir da década de 1990, concretamente em 1995, assiste-se a um boom de instituições, com a aderência às políticas neoliberais, o número de instituições cresceu para 49 instituições de ensino superior (4900\%), sendo que 18 são públicas e 31 são privadas. Quanto ao acesso, obviamente com o nascimento de instituições de ensino superior privadas e a privatização da universidade pública, o seu acesso passou a limitar grande parte da população.

Este artigo analisa expansão do ensino superior em Moçambique destacando as influências globais nas políticas nacionais.

O tema é bastante relevante pois, visualiza desigualdades sociais no acesso que vão sendo criadas durante a expansão do ensino superior, advindas das influências globais nas políticas nacionais. De recordar que Moçambique é um país constitucionalmente democrático e de justiça social (Artigo 1, CR 2004).

\section{Referencial Teórico}

Para Rodrigues (2014, p. 17), a análise das políticas públicas tem como objeto de estudo as decisões políticas e os programas de acção dos governos, interrogando-se sobre a génese dos problemas que tais decisões procuram resolver, sobre as soluções formuladas e as condições da sua implementação.

Dentre vários modelos de análise de políticas que nos ajudam a compreender a política pública, para esta pesquisa adoptou-se a perspectiva da Abordagem do Ciclo de Políticas (Policy Cycle Approach) de Stephen Ball (1994) e Richard Bowe, Stephen Ball e Anne Gold (1992), (apud MAINARDES, 2006). Essa abordagem trabalha com um ciclo contínuo nas policies, constituído por cinco contextos: $O$ contexto de influência analisa a génese da política e suas influências; o contexto do texto, que analise o texto da política; o contexto da prática, a sua implementação; o contexto dos resultados, a análise dos efeitos do ponto de vista de justiça social, e, por último, o contexto da estratégia política que envolve a identificação de ações sociais e políticas necessárias para o ajuste das desigualdades existentes.

\section{Metodologia}

${ }^{7}$ Curso pós-laboral refere-se aos programas de formação superior privados que ocorrem dentro das IES públicas no regime noturno.

\begin{tabular}{l|l} 
REVISTA & Interritórios | Revista de Educação \\
interritórios & $\begin{array}{l}\text { Universidade Federal de Pernambuco, } \\
\text { Caruaru, BRASIL | V.6 N.10 [2020] }\end{array}$
\end{tabular}


A pesquisa é exploratória com abordagem qualitativa. Os procedimentos da pesquisa foram o Estudo Documental feito através de regulamentos, editais, leis, relatórios, mapas estatísticos; a Pesquisa Bibliográfica através de artigos, teses e bibliografia afim; o Estudo de Campo através da entrevista e da observação em 3 IES públicas nomeadamente a Universidade Eduardo Mondlane (UEM), a Universidade Pedagógica (UP), o Instituto Superior de relações Internacionais(ISRI).

A estrutura de análise obedece aos cinco contextos anteriormente referenciados: o contexto de influência; o contexto do texto; o contexto da prática; o contexto dos resultados ou efeitos; e o contexto da estratégia política.

\section{Resultados e Discussões}

Contexto de Influências: a Influência Global na Expansão do Ensino Superior em Moçambique.

Analisar o contexto de influência é analisar as origens da política, a sua história, os embates e consensos em volta dela, requer, ainda, pela sua complexidade, analisar as influências globais ou internacionais no processo de formulação de políticas nacionais.

Tendo como referência os estudos de Ball (1994), Bowe, Ball e Gold (1992), Mainardes (2006) assume que a influência internacional no processo de formulação de políticas nacionais se faz sentir basicamente pela circulação internacional de ideias e pelo patrocínio e imposição de algumas soluções oferecidas e recomendadas por organismos internacionais tais como o Banco Mundial, o Fundo Monetário Internacional, a OCDE e a UNESCO.

De recordar que aquando da crise económica na década de 80, Moçambique solicitou apoio ao Banco Mundial e ao Fundo Monetário Internacional, que recomendaram reformas do Estado que levaram a privatização de serviços sociais, a diminuição dos gastos do Estado com serviços sociais, e estes organismos também fazem parte do grupo de financiadores do Orçamento Geral do Estado (OGE) ${ }^{8}$, e por essa posição, tendem a influenciar as prioridades governamentais, de modo que as políticas a implementar estejam de acordo com o que é prioritário para esses organismos.

\footnotetext{
${ }^{8} \mathrm{O}$ orçamento é uma previsão de receitas e de despesas de um país ou um organismo para um determinado período. No caso do Orçamento Geral do Estado, o período normalmente é de um ano. O Estado deve prever as receitas de modo que estas possam garantir a cobertura das despesas. 
Basílio (2010), sustenta esta posição afirmando que em Moçambique, desde 1984, uma boa parte das políticas sociais são definidas, financiadas e fiscalizadas por instituições não governamentais.

Exemplos dessa influência são a prioridade que teve a educação básica na Política Nacional de Educação (PNE) e nos Planos Estratégicos de Educação (PEE's) que foram aprovados na década de 1990, decisões partidas da Conferência Mundial de Educação para Todos de Jomtien em 1990, convocada e organizada pela UNESCO, Banco Mundial, UNICEF e PNUD.

A implementação do Plano Estratégico do Ensino Superior (2000-2010), que incluía a expansão do ensino superior, foi efetivado empréstimo do Banco Mundial.

Leher (1999) afirma que o Banco Mundial se tornou uma espécie de ministério da educação dos países periféricos ao estabelecer condicionalidades em termos das políticas sociais a serem adotadas pelos países tomadores de empréstimos do Fundo Monetário Internacional e do Banco Mundial.

As reformas efetuadas no ensino superior em Moçambique - fomento à diferenciação de instituições, incluindo a possibilidade de atuação de instituições do ensino superior privadas, diferenciação de fontes de financiamento do ensino superior, incluindo cobrança de taxa a estudantes, redefinição da função do Estado no ensino superior - não devem ser vistas como uma inovação das instituições do ensino superior, pois fazem parte do lote de medidas do Banco Mundial para com os países em desenvolvimento. Essas medidas fundamentaram-se nas quatro orientações apresentadas pelo Banco Mundial no relatório La enseñanza superior - las lecciones derivadas de la experiencia, publicado em 1994, como estratégias para a educação nos países em desenvolvimento:

- Fomentar la mayor diferenciación de las instituciones, incluido el desarrollo de instituciones privadas;

- Proporcionar incentivos para que las instituciones públicas diversifiquen las fuentes de financiamiento, por ejemplo, la participación de los estudiantes en los gastos y la estrecha vinculación entre el financiamiento fiscal y los resultados;

- Redefinir la función del gobierno en la enseñanza superior;

- Adoptar políticas que estén destinadas a otorgar prioridad a los objetivos de calidad y equidade (BANCO MUNDIAL, 1995, p. 04).

O Banco Mundial através do relatório inicia de forma clara o carácter mercantil da sua política de educação superior nos países em desenvolvimento contrastando com as condições económicas desses países, cujas as desigualdades de renda são extremas e a maioria vive abaixo da pobreza. 
Aliado ás fragilidades económicas do país que levaram a privatização ensino superior no geral e ensino superior público em especial, há a destacar também a fraca atuação das Organizações da Sociedade Civil (OSC) moçambicanas nas reivindicações, pois, na sua maioria formam formados no período monopartidário pela FRELIMO e continuam a ela ligadas, o que as torna mais frágeis para externar reivindicações de modo autônomo ao governo. $O$ outro fator que fragiliza essas Organizações da Sociedade Civil é a sua dependência financeira que se explica primeiro porque, por lei, as organizações são obrigadas a estarem ligadas a um órgão do governo na área em que operam para receberem apoio financeiro e segundo porque, recebem apoio do próprio Estado.

Contexto de Produção do Texto: A Expansão e o Acesso ao Ensino Superior na Legislação Nacional

O contexto da produção de textos relaciona-se com os textos que representam a política. Pode envolver a análise de textos e documentos, entrevistas com autores de textos de políticas, entrevistas com aqueles para os quais tais textos foram escritos e distribuídos. (MAINARDES 2006, p. 59).

Nesta pesquisa não foi encontrado um documento de âmbito nacional sobre expansão e acesso do ensino, mas as intenções são expressas nos principais documentos legais do país, como a Constituição da República (2004), a Lei 6/92 do Sistema Nacional de Educação, a Lei 27/2009 do Ensino Superior, o Plano Nacional de Educação (1995), o Plano Estratégico do Ensino Superior (2012 - 2020), a Estratégia de Financiamento do Ensino Superior - 2013 e a Plano Estratégico de Educação e Cultura (2006 - 2010/11) que podem constituir a política enquanto texto. Nestes textos, é possível sinalizar intenções do Estado na expansão e no acesso ao ensino superior tendo em conta a justiça social, a partir de preceitos sinalizados nos textos como a garantia de equidade e igualdade de oportunidades, democratização de ensino, expansão e acesso equitativo do superior, massificação de acesso, assistência estudantil através da atribuição de bolsas, entre outros como pode-se visualizar no quadro 1 .

Quadro 1 - A Expansão e o Acesso ao Ensino Superior na Legislação Nacional

\begin{tabular}{|c|c|}
\hline Lei & Preceitos \\
\hline $\begin{array}{l}\text { Constituição da República de Moçambique - } 2004 \\
\text { Art. } 1 \text { República de Moçambique é um Estado } \\
\text { independente, soberano, democrático e de justiça social } \\
\text { Art. 88, Na República de Moçambique a educação constitui } \\
\text { direito e dever de cada cidadão. } \\
\text { Art. 114, Acesso às IES públicas devem garantir a } \\
\text { igualdade e equidade de oportunidades e a } \\
\text { democratização do ensino (...) }\end{array}$ & $\begin{array}{l}\text { Estado de justiça social. } \\
\text { Direito de todos a educação } \\
\begin{array}{l}\text { lgualdade e equidade de } \\
\text { oportunidades } \\
\text { democratização do ensino. }\end{array}\end{array}$ \\
\hline Lei de Educação - 6/92 & \\
\hline
\end{tabular}




\begin{tabular}{|c|c|}
\hline $\begin{array}{l}\text { Art. 1. Princípios Gerais } \\
\text { a) A educação é direito e dever de cada cidadão. } \\
\text { Art. 4. Para permitir a frequência do ES e de forma a } \\
\text { atenuar os efeitos discriminatórios decorrentes de } \\
\text { desigualdades econômicas e regionais ou desvantagens } \\
\text { sociais previas: a) O Estado deve garantir bolsas de estudo } \\
\text { com quotas pré-estabelecidas e outras formas de apoio } \\
\text { para as classes de menor rendimento econômico e para } \\
\text { cada região. Estas bolsas poderão ser atribuídas a } \\
\text { estudantes de IES estatais e privadas. }\end{array}$ & $\begin{array}{l}\text { O Estado deve garantir } \\
\text { políticas Sociais (bolsas de } \\
\text { estudo com quotas pré- } \\
\text { estabelecidas e outras formas } \\
\text { de apoio para as classes de } \\
\text { menor rendimento econômico } \\
\text { e para cada região). }\end{array}$ \\
\hline $\begin{array}{l}\text { Lei do Ensino Superior - 27/2009 } \\
\text { Art. } 2 \text { (Princípios) } \\
\text { Para além dos princípios gerais e pedagógicos definidos } \\
\text { nos artigos } 1 \text { e } 2 \text { da Lei no } 6 / 92 \text {, de } 6 \text { de maio, as IES } \\
\text { atuam de acordo com os seguintes princípios: } \\
\text { a) Democracia e respeito pelos direitos humanos; } \\
\text { b) Igualdade e não discriminação; } \\
\text { Art. } 5 \text { (Bolsas de estudo) } \\
\text { 1. Para permitir a frequência do ES e para atenuar os } \\
\quad \text { efeitos discriminatórios decorrentes de } \\
\quad \text { desigualdades económicas e sociais, o Estado } \\
\quad \text { garante bolsas de estudo (...) }\end{array}$ & $\begin{array}{l}\text { Respeitar e Garantir os } \\
\text { Direitos Humanos (Igualdade e } \\
\text { não discriminação); } \\
\text { garantir bolsas de e formas de } \\
\text { apoio aos estudantes de } \\
\text { menor rendimento económico } \\
\text { de instituições públicas e } \\
\text { privadas de ES. }\end{array}$ \\
\hline $\begin{array}{l}\text { Plano Estratégico do Ensino Superior (2012 - 2020) } \\
\text { O PEES 2012-2020 tem, como uma das missões, } \\
\text { "Promover a participação e o acesso equitativos, no ES" } \\
\text { [...] através de medidas que vão desde a diversificação das } \\
\text { IES, aumento do volume de bolsas de estudo... (PEES } \\
\text { 2012-2020, p.2) } \\
\text { Objetivo Estratégico: Promover a expansão e o acesso } \\
\text { equitativo ao ES com padrões internacionais de qualidade. }\end{array}$ & $\begin{array}{l}\text { Expansão e Acesso equitativos } \\
\text { no ES através diversificação } \\
\text { de IES e aumento do volume } \\
\text { de bolsas de estudo. }\end{array}$ \\
\hline $\begin{array}{l}\text { Estratégia de Financiamento do Ensino Superior } \\
\text { (EFES) -2013 } \\
\text { Um dos objetivos do EFES: } \\
\text { c. Promover a equidade no acesso à formação e ES; } \\
\text { Um dos princípios orientadores: Equidade no acesso para } \\
\text { assegurar que todos os cidadãos, independentemente da } \\
\text { sua condição econômica e social, tenham a possibilidade } \\
\text { de aceder ao ES. }\end{array}$ & $\begin{array}{l}\text { O Estado deve garantir bolsas } \\
\text { de estudo para garantir } \\
\text { equidade do acesso de todos } \\
\text { ao ES, independentemente da } \\
\text { condição econômica e social } \\
\text { do estudante. }\end{array}$ \\
\hline $\begin{array}{l}\text { Plano Estratégico de Educação e Cultura (2006 - } \\
\text { 2010/11) } \\
\text { Aumentar o acesso, reduzindo as disparidades geográficas } \\
\text { e de gênero. } \\
\text { Criação do fundo de bolsas para estudantes cujos recursos } \\
\text { financeiros próprios são insuficientes. }\end{array}$ & $\begin{array}{l}\text { Criação do fundo de bolsas } \\
\text { para estudantes com recursos } \\
\text { financeiros insuficientes. }\end{array}$ \\
\hline
\end{tabular}

Fonte: Mechisso (2020).

\section{Contexto da Prática: Como é que vem se expandindo o Ensino Superior?}

A análise do contexto da prática implica uma inserção nas instituições e em espaços onde a política é desenvolvida, por meio de observações ou pesquisa etnográfica, e ainda entrevistas com profissionais da educação, pais, alunos, etc.

Com aprovação da nova Constituição da República (1990), da Lei de Educação (Lei 6/92), da 1르 Lei do Ensino Superior (Lei 1/93) e do Plano Nacional 
de Educação (1995), alinhados ás diretrizes neoliberais do Banco Mundial e do Fundo Monetário Internacional, novos elementos entraram na educação moçambicana e abriu-se caminho para a expansão vertiginosa do ensino superior, tanto público como privado. No que diz respeito ao número de instituições de ensino superior, houve maior expansão do setor privado, das 49 instituições de ensino superior existentes, 31 foram privadas corresponde a $62,5 \%$ e apenas 18 , o que corresponde a $37,5 \%$ foram as públicas.

\section{Gráfico 1- Crescimento das IES (setores público e privado)}

Crescimento das IES (Públicas e Privadas)

60

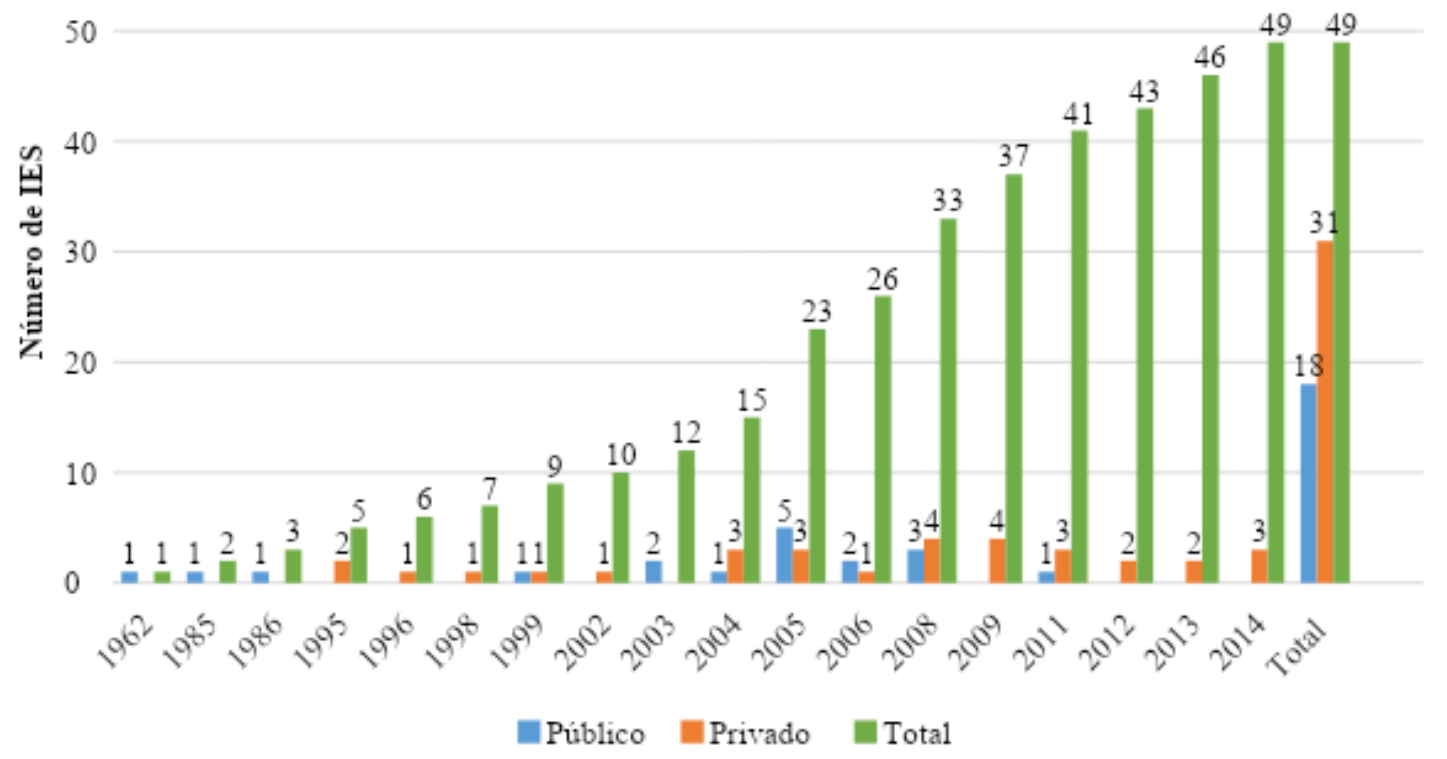

Fonte: Ministério da Ciência e Tecnologia, Ensino Superior e Técnico-Profissional.

Como se pode verificar, houve um crescimento bastante significativo de instituições de ensino superior, porém, com maior ênfase para instituições de ensino superior privadas.

Quadro 2 - Instituições de Ensino Superior de Moçambique (Até 2017)

\begin{tabular}{|l|l|c|l|c|}
\hline Ordem & IES Públicas & $\begin{array}{c}\text { Ano de } \\
\text { Criação }\end{array}$ & \multicolumn{1}{|c|}{ IES Privadas } & Ano de Criação \\
\hline 1. & UEM & 1962 & UCM & 1995 \\
\hline 2. & UP & 1985 & ISPU (Apolitécnica) & 1995 \\
\hline 3. & ISRI & 1986 & ISUTC & 1999 \\
\hline 4. & ACIPOL & 1999 & ISCTEM & 1996 \\
\hline 5. & ISCISA & 2003 & UMBB & 1998 \\
\hline
\end{tabular}




\begin{tabular}{|c|c|c|c|c|}
\hline 6. & AM & 2003 & UDM & 2002 \\
\hline 7. & ESCN & 2004 & USTM & 2004 \\
\hline 8. & ISCAM & 2005 & UJPM & 2004 \\
\hline 9. & ISPG & 2005 & ESEG & 2004 \\
\hline 10. & ISPM & 2005 & ISC & 2005 \\
\hline 11. & ISPT & 2005 & ISET & 2005 \\
\hline 12. & ISAP & 2005 & ISFIC & 2005 \\
\hline 13. & UniLúrio & 2006 & ISDB & 2006 \\
\hline 14. & UniZambeze & 2006 & ISTEG & 2008 \\
\hline 15. & ESJ & 2008 & ISM & 2008 \\
\hline 16. & ISArC & 2008 & ISCIM & 2008 \\
\hline 17. & ISPS & 2008 & ISMA & 2008 \\
\hline 18. & ISEDEF & 2011 & ISGCOF & 2009 \\
\hline 19. & & & ISTAC & 2009 \\
\hline 20. & & & INSCIG & 2009 \\
\hline 21. & & & ISCTAC & 2009 \\
\hline 22. & & & UMA & 2011 \\
\hline 23. & & & ISGN & 2011 \\
\hline 24. & & & UAM & 2011 \\
\hline 25. & & & ISEDEL & 2012 \\
\hline 26. & & & ISMU & 2012 \\
\hline 27. & & & ISG & 2013 \\
\hline 28. & & & ESGCS & 2013 \\
\hline 29. & & & UMUM & 2014 \\
\hline 30. & & & ISEAD & 2014 \\
\hline 31. & & & ISGE-GM & 2014 \\
\hline
\end{tabular}

Fonte: Ministério da Ciência e Tecnologia, Ensino Superior e Técnico-Profissional ${ }^{9}$

Quanto à cobertura educacional nos três períodos históricos em análise, o número de estudantes apenas aumentou: eram 2.433 estudantes no período colonial; no período pós-independência até 1989, o número cresceu para 5.000 estudantes, e, em 2016, para 196.801, ou seja, no primeiro período pósindependência, até a transição para o sistema capitalista, o número de estudantes mais que dobrou. No período capitalista, com a adopção de políticas

${ }^{9}$ Disponível em: http://www.mctestp.gov.mz/?q=content/institui\%C3\%A7\%C3\%B5es-de-es 
neoliberais, o número cresceu em cerca de $8.090 \%$, em relação ao período colonial.

E aumentou em cerca de $3.940 \%$, do período socialista para o capitalista. Reitera-se que a privatização do ensino Superior e a oferta no ensino público de cursos no regime privado contribuíram bastante para esse crescimento.

\section{Contexto dos Resultados ou Efeitos: E o acesso?}

O quarto contexto é dos resultados ou efeitos, e preocupa-se com o impacto da política, as questões de justiça, igualdade e liberdade individual.

É a reflexão sobre questões conjunturais e sobre as desigualdades que são criadas pela política e podem ser detectadas pela pesquisa criteriosa do contexto da prática por meio de observações prolongadas, entrevistas ou pesquisa etnográfica (MAINARDES, 2006, p. 60).

Os dados referentes à evolução de matrículas entre 2000 e 2016 revelam um crescimento total da população estudantil - de 13.592 para 196.801, cerca de $1447.9 \%$ de crescimento, porém, há a destacar que apesar dos dados do acesso mostrarem que o sector público ofereceu maior acesso que o privado, há a destacar que a maior parte das vagas oferecidos pelas instituições de ensino superior públicas no seu todo eram maioritariamente destinados aos regimes pós-laboral e ensino a distância (privados) como veremos mais adiante.

Tabela 1 - Evolução das Matriculas e Número de Instituições de Ensino Superior Públicas e Privadas - Moçambique (2000 - 2016)

\begin{tabular}{|c|c|c|c|c|c|c|c|c|c|c|c|}
\hline \multirow[t]{2}{*}{ Ano } & \multicolumn{4}{|c|}{ Setor Público } & \multicolumn{4}{|c|}{ Setor Privado } & \multirow[t]{2}{*}{ Total } & \multirow[t]{2}{*}{ T. F } & \multirow[t]{2}{*}{$\% \mathbf{F}$} \\
\hline & Matr. & $\mathbf{F}$ & $\%$ & IES & Matr. & $\mathbf{F}$ & $\%$ & IES & & & \\
\hline 2000 & 9644 & & 71.0 & 4 & 3948 & & 29.0 & 5 & 13592 & 909 & 6.7 \\
\hline 2001 & 11655 & & 82.3 & 4 & 2514 & & 17.7 & 5 & 14169 & 4677 & 33 \\
\hline 2002 & 11235 & & 64.6 & 4 & 6162 & & 35.4 & 6 & 17397 & 3516 & 20.2 \\
\hline 2003 & 14355 & & 82.5 & 4 & 3042 & & 17.5 & 6 & 17397 & 3516 & 20.2 \\
\hline 2004 & 15113 & & 67.9 & 6 & 7143 & & 32.1 & 9 & 22256 & 7022 & 31.6 \\
\hline 2005 & 18863 & & 66.7 & 7 & 9435 & & 33.3 & 12 & 28298 & 9376 & 33.1 \\
\hline 2006 & 32090 & & 74.2 & 12 & 11143 & & 25.8 & 13 & 43233 & 14531 & 33.6 \\
\hline 2007 & 51001 & & 80.3 & 14 & 12475 & & 19.7 & 13 & 63476 & 24201 & 38.1 \\
\hline 2008 & 5643 & & 77.7 & 14 & 16817 & & 22.3 & 16 & 75460 & 29106 & 38.6 \\
\hline 2009 & 60949 & & 75.0 & 17 & 20301 & & 25.0 & 21 & 81250 & 30826 & 37.9 \\
\hline 2010 & 72639 & & 71.7 & 17 & 28726 & & 28.3 & 21 & 101362 & 38852 & 38.3 \\
\hline *2015 & 116037 & 45647 & 66.4 & 18 & 58765 & 28513 & 33.6 & 31 & 174802 & 74160 & 42.4 \\
\hline *2016 & 119522 & 48654 & 60.7 & 18 & 77279 & 38502 & 39.3 & 31 & 196801 & 87156 & 44.3 \\
\hline
\end{tabular}

Fonte: Mechisso (2020)

Legenda: Matr. - Matrículas; F - Matrículas em Feminino; T.F. - Total em Feminino; \% F Percentagem em Feminino 
Quanto ao género, a população feminina aumentou a sua presença no ensino superior, de 909 no ano 2000, para 87.156 no ano 2016 (9.583,4\%), ou seja, de $6.7 \%$ da representatividade feminina em 2000 , em relação à população masculina, a proporção cresceu para $44.3 \%$ em 2016. Apesar de ter havido melhorias assinaláveis no equilíbrio de gênero, a presença feminina continua ainda baixa no ensino superior situando-se, em média, nos $43 \%$.

Quanto a distribuição da rede escolar pelo país, dados do Conselho Nacional de Avaliação de 2016 e do Ministério da Ciência, Tecnologia, Ensino Superior e Técnico Profissional de 2015, apontavam que as 49 instituições de ensino superior existentes no país encontravam-se distribuídas na seguinte proporção: Cidade de Maputo com 47\%, Província de Maputo com 22\%, Gaza $2 \%$, Inhambane $2 \%$, Manica $4 \%$, Sofala $12 \%$, Tete $7 \%$, Zambezia $0 \%$, Cabo Delegado $0 \%$ e Niassa $0 \%$.

\section{Gráfico 2 - Instituições de Ensino Superior por Províncias - 2017}

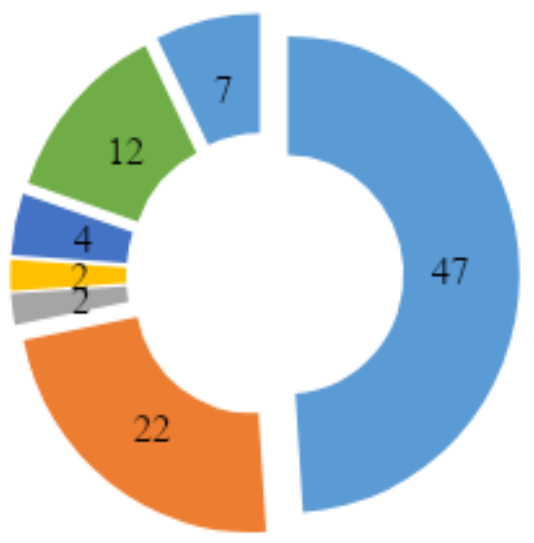

Cidade de Maputo
Maputo Província
Gaza
Inhambane
I Manica
=Sofala
= Tntn

Fonte: Conselho Nacional de Avaliação (2016) e Ministério da Ciência, Tecnologia, Ensino Superior e Técnico Profissional (2015)

A Cidade de Maputo (capital) com estatuto de província e a província de Maputo no sul do país, ambas cobriam $69 \%$ do número de instituições de ensino superior das existentes, havendo províncias sem nenhuma instituição, ou seja, a população de Maputo ao sul do país tem mais oportunidade de acesso ao ensino superior em relação a população de todas as 9 províncias juntas.

Com relação ao número de vagas de acesso dentro da universidade pública, dados de 2017, das 3 Principais IES, nomeadamente, a Universidade 
Eduardo Mondlane, a Universidade Pedagógica e o Instituto Superior de Relações Internacionais mostravam uma tendência de maior oferta de ensino de carácter privado em relação ao ensino regular e com o agravante do número de bolsas de estudo ofertadas serem bastante reduzidas.

Tabela 2. Cenário do Acesso das 3 Principais IES Públicas - 2017

\begin{tabular}{lr|r|r|r}
\hline Universidade Pública & Regular & $\begin{array}{c}\text { Pós- } \\
\text { laboral }\end{array}$ & EAD & $\begin{array}{c}\text { Bolsas de } \\
\text { Estudo }\end{array}$ \\
\hline Universidade Eduardo Mondlane & 3015 & 1730 & 529 & 399 \\
Universidade Pedagógica & 5445 & 6.760 & 4.280 & 288 \\
ISRI & 200 & 200 & 0 & 60 \\
\hline
\end{tabular}

Fonte: Edital de Ingresso e Edital de Bolsas de Estudo - 2017

\section{Contexto da Estratégia Política}

Por fim, o contexto de estratégia política, que envolve a identificação de ações sociais e políticas necessárias para o ajuste das desigualdades criadas ou produzidas pela política estudada.

O contexto da estratégia política exige que o pesquisador assuma a responsabilidade ética com o tema investigado, apresentando estratégias e atividades para se lidar mais eficazmente com as desigualdades identificadas na política. Tais estratégias - que podem ser genéricas ou mais específicas (MAINARDES, 2006, p. 54).

Com vista a minimizar as disparidades verificadas na expansão do ensino superior, propõe-se de forma geral, a aprovação de uma política nacional para a expansão e acesso ao ensino superior, capaz de articular as ações isoladas das instituições de ensino superior, controlar e garantir o equilíbrio no acesso ao ensino superior por classe social, região, por género, entre outros. $E$ de forma específica,

O mapeamento dos desequilíbrios na expansão e do acesso ao ensino superior de modo a corrigir as disparidades existentes;

Mais alocação de bolsas de Estudo para permitir o acesso de estudantes provenientes de famílias socioeconomicamente desfavorecidas e das províncias;

Desprivatização do ensino superior ou então, a repartição de responsabilidades entre o público e o privado com relação ao acesso ao ensino superior, poderia garantir maior equilíbrio entre a expansão e acesso para todos. 


\section{Considerações Finais}

A expansão e o acesso ao ensino superior em Moçambique são um processo incongruente, pois, a expansão, não significou em simultâneo o acesso para todos. Houve expansão das instituições do ensino superior públicas e privadas, mas o carácter mercadológico do seu acesso influenciado por políticas globais, foi excluindo a maior parcela da população que é a pobre, considerando que mais da metade da população $60 \%$ vive abaixo da linha de pobreza. As instituições de ensino superior públicas passaram a oferecer maior parte do seu acesso nos cursos pós-laborais e à distância, cuja frequência nestes regimes é mediante o pagamento de taxas mensais, o que vem tornando o acesso ás instituições de ensino superior públicas também excludente, agravando ainda a exclusão pelo facto, delas não possuírem políticas de assistência estudantil capazes de apoiar os estudantes socioeconomicamente carenciados. Para além de que as que possuem políticas de assistência estudantil, as mesmas são bastante precárias em qualidade e quantidade.

No que tange a distribuição da rede escolar pelo país, verificam-se desigualdades regionais, há maior concentração de instituições de ensino superior nas Províncias de Maputo, onde chegam a concentrar cerca $70 \%$ do número de instituições de ensino superior. Associado ao fator localização, também se verificam desequilíbrios de género no acesso ao ensino superior e as políticas de assistência estudantil, o género feminino está em menor representatividade no ensino superior, facto que pode estar associado a localização das instituições do ensino superior e por falta de assistência estudantil pode estar a inibe-las ao acesso.

A busca por fontes de receitas próprias das instituições do ensino superior, como são os casos da oferta de ensino do pós-laboral, a distância, a fraca e falta assistência estudantil enquadrados nas políticas do Banco Mundial e do Fundo Monetário Internacional, tem vido retirar os direitos fundamentais dos moçambicanos, o direito à educação e o princípio de justiça social preceituado da Constituição da República de 2004.

\section{REFERÊNCIAS}

BANCO MUNDIAL. La Enseñanza Superior - las lecciones derivadas de la experiencia. Washington: Banco Mundial, 1995.

BASÍLIO, Guilherme. O Estado e a Escola na Construção da Identidade Política Moçambicana. 2010. Tese (Doutorado em Educação) - Pontifícia Universidade Católica de São Paulo, São Paulo, 2010. 
LEHER, Roberto. Um Novo Senhor da Educação? A política educacional do Banco Mundial para a periferia do capitalismo. Outubro Revista, São Paulo, v. 1, n. 3, p. 1930, 1999.

MAINARDES, Jefferson. Abordagem do Ciclo de Políticas: uma contribuição para a análise de políticas educacionais. Educação e Sociedade, Campinas, v. 27, n. 94, p. 47-69, jan./abr. 2006.

MCTESTP - Ministério de Ciência e Tecnologia, Ensino Superior e Técnico Profissional. Instituições de Ensino Superior. Maputo, 2015. Disponível em: <http://www.mctestp.gov.mz/?q=content/institui\%C3\%A7\%C3\%B5es-de-es>. Acesso em: 31 out. 2017.

MECHISSO, Guedes Basilio. EXPANSÃO E O ACESSO AO ENSINO SUPERIOR EM MOÇAMBIQUE: UM PROCESSO INCONGRUENTE. In: Anais do I Congresso Nacional em Políticas, Práticas e Gestão da Educação. Anais...Garanhuns (PE) UPE, 2020. Disponível em: <https//www.even3.com.br/anais/cnppge/213504EXPANSAO-E-O-ACESSO-AO-ENSINO-SUPERIOR-EM-MOCAMBIQUE--UMPROCESSO-INCONGRUENTE>. Acesso em: 30/01/2020

MECHISSO, Guedes. Políticas de Assistência Estudantil no Ensino Superior em Moçambique: Passado, Presente e Desafios. 2017. (Doutorado em Educação) Universidade Federal do Rio Grande do Sul.

MOÇAMBIQUE. Assembleia da República. Constituição da República. Boletim da República, Maputo, n. 51 (série I), 22 dez. 2004. Maputo: Imprensa Nacional, 2004.

MOÇAMBIQUE. Assembleia da República. Lei no 27/2009, de 29 de setembro - Lei do Ensino Superior. Boletim da República, Maputo, 2009. Maputo: Imprensa Nacional, 2009.

MOÇAMBIQUE. Assembleia da República. Lei no 6/92: Sistema Nacional de Educação. Boletim da República, Maputo, n. 19 (série I), 6 de maio 1992. Maputo: Imprensa Nacional, 1992.

MOÇAMBIQUE. Ministério da Educação. Plano Estratégico de Educação e Cultura 2012-2016. Maputo: Imprensa Universitária, 2012.

MOÇAMBIQUE. Ministério da Educação. Plano Estratégico para o Ensino Superior 2012-2020. Maputo: Imprensa Universitária, 2012.

MOÇAMBIQUE. Política Nacional de Educação e Estratégias de Implementação. Resolução no 8/95, de 22 de agosto de 1995. Aprova a Política Nacional da Educação. Boletim da República, Maputo, n. 41 (série I), 1995. Maputo: Imprensa Nacional, 1995.

RODRIGUES, Maria de Lurdes. Exercícios de Análise de Políticas Públicas.

Lisboa: Imprensa Nacional - Casa da Moeda, 2014. 